\title{
Correction: Can't see the wood for the trees: confounders, colliders and causal inference- a statistician's approach
}

Huang B, Szczesniak R. Can't see the wood for the trees: confounders, colliders and causal inference- a statistician's approach. Thorax 2019;74:323-325. doi: 10.1136/thoraxjnl-2018-212780

Significant changes have been made to the text of this article, including Table 1 , since it was first published online and in print. The correct version is available online here: http://dx.doi. org/10.1136/thoraxjnl-2018-212780

(C) Author(s) (or their employer(s)) 2019. No commercial re-use. See rights and permissions. Published by BMJ.

Thorax 2019;74:e2. doi:10.1136/thoraxjnl-2018-212780corr1

(D) Check for updates 